\title{
Simulation Analysis on Dangerous Goods Accident in Container Terminals
}

\author{
Qiao Jianzhe ${ }^{1}$, Shou Youping ${ }^{1 *}$, and Zhao Junjie ${ }^{1}$ \\ ${ }^{1}$ Laboratory of Waterway Environmental Protection Technology, Tianjin Research Institute for Water Transport Engineering, Tianjin \\ 300456, China
}

\begin{abstract}
In general, transportation of Dangerous Goods in the port and shipping industry is mainly based on the container. This paper summarized the types of container terminal accidents, and put forward a method to select source of pollutants, and showed pollution range of typical accidents, provided the basis for the decision of management department. Taking a domestic container terminal as an example, the calculation results show that, under the premise of taking corresponding measures, the pollution range of accidents is not wide, and the risk is controllable.
\end{abstract}

\section{INTRODUCTION}

As the container has a high transport efficiency and convenience, about $76.2 \%$ of the world's chemical dangerous goods transport through the sea. Due to the special potential danger of the dangerous goods itself, in the event of an abnormal accident, it will cause harmful impact on the environment. In this paper, we will study the loading and unloading of container terminals, analyze the typical risk accidents with high probability of accidents, and give the range of pollutant diffusion. This paper provides technical support for environmental impact assessment. Make emergency plan and provide basis for managing corresponding type of project.

\section{TYPICAL TYPES OF CONTAINER TERMINALS RISK ACCIDENTS}

Regardless of stockpiling the main causes of Container Terminals risk accidents include (1) water transport; (2) loading and unloading; (3)land transport.[1]

\subsection{Water transport}

The water transport process includes the ship sailing process, berthing of the port, anchorage and so on. Water pollution accidents are divided into two categories, namely oil pollution accidents and chemical leakage accidents, mostly caused by ship traffic accidents. According to the law of the accident, the ship accident occurred mainly in the port and the channel. According to a number of accident types and accident-induced statistical analysis, the accident occurred in the port or coastal areas. Statistical inductions of typical accident are listed in Table 1.
Tab 1. Induction of typical accidents

\begin{tabular}{|c|c|c|}
\hline location & Source & cause \\
\hline Seaway & Ships & Ships collision \\
\hline Anchorage & Ships & Ships collision, Operational errors \\
\hline $\begin{array}{c}\text { Harbour } \\
\text { basin }\end{array}$ & Ships & $\begin{array}{c}\text { Ships collision, The ships collide } \\
\text { with the dock, Operational errors }\end{array}$ \\
\hline
\end{tabular}

\subsection{Loading and unloading}

Container transport itself is a safe form of transport. Large-scale container pollution incidents of loading and unloading rarely occur. According to the characteristics of dangerous goods loading and unloading in this project, the pollution accident and the cause of the process are listed in Table 2.

Tab 2. Accident types and causes of loading and unloading process

\begin{tabular}{|c|c|c|}
\hline $\begin{array}{l}\text { Accident } \\
\text { type }\end{array}$ & Cause & $\begin{array}{c}\text { The consequences } \\
\text { of the accident }\end{array}$ \\
\hline $\begin{array}{l}\text { Leakage of } \\
\text { dangerous } \\
\text { goods }\end{array}$ & $\begin{array}{l}\text { Operational errors, } \\
\text { equipment failure, } \\
\text { technical defects lead } \\
\text { to damage to the ships, } \\
\text { causing leakage } \\
\text { accidents }\end{array}$ & \multirow{2}{*}{$\begin{array}{c}\text { Leakage of } \\
\text { dangerous goods } \\
\text { with rainwater } \\
\text { discharge into the } \\
\text { ocean caused } \\
\text { water pollution; } \\
\text { Gaseous } \\
\text { dangerous goods } \\
\text { spread to the } \\
\text { atmosphere to the } \\
\text { surrounding staff } \\
\text { poisoning }\end{array}$} \\
\hline $\begin{array}{l}\text { Dangerous } \\
\text { goods } \\
\text { explosion }\end{array}$ & $\begin{array}{l}\text { Operational errors, } \\
\text { equipment failure, } \\
\text { technical defects lead } \\
\text { to damage to the ships, } \\
\text { in extreme conditions } \\
\text { caused by dangerous } \\
\text { goods explosion }\end{array}$ & \\
\hline
\end{tabular}

* Corresponding author: syp851228@126.com 


\subsection{Land transport}

When vehicle is running, due to drivers, traffic conditions, climate and other reasons may occur collision. [2]Bad weather conditions, fire, fatigue driving, drunk driving are the main reason (Table 3 ).

Tab 3. Reference for typical transport accident

\begin{tabular}{|c|c|}
\hline $\begin{array}{c}\text { Accident } \\
\text { type }\end{array}$ & Cause \\
\hline Collision & $\begin{array}{c}\text { Bad weather conditions, fire, fatigue driving, } \\
\text { drunk driving }\end{array}$ \\
\hline Leakage & $\begin{array}{c}\text { Traffic accident, collision, packaging damage, } \\
\text { overflow spill }\end{array}$ \\
\hline
\end{tabular}

The most harmful effect of the transport of dangerous goods is highly toxic and polluting substances spilled into the surface waters because the hazardous substances in the event of leakage into the waters will cause water pollution, which has harmful environmental impact and damage. In the event of such an accident, the relevant management must give high priority. But these dangerous goods are sealed barrels of transport, so there is little chance of leakage. During the operation period, there is a certain risk of transportation accident. Large container vehicles contain dangerous goods when they contain dangerous goods. [3]

\section{SELECTION OF SPECIES AND SOURCE}

\subsection{Leakage into the sea}

\subsubsection{Selection of goods species}

The main principles of screening for incoming chemicals are the selection of the largest volume of goods and the most serious impact on seawater quality. The goods species are selected according to the region similar projects, from the the proportion of transport. The most serious impact on the quality of seawater is based on all the goods in the seawater quality indicators of the most stringent to determine. The selection of the species should fit the corresponding water quality standards.

\subsubsection{Selection of source}

With the container terminal loading and unloading operations become more specialized and standardized, the whole container fall into the sea, the box of small packaging units at the same time leakage, resulting in a transiently high source, the probability of such a situation is very low; there is no guidance for the emergency state. This paper suggests considering small package leaks as a source of risk prediction.

\subsection{Leakage into the air}

Gaseous material screening mainly refers to the following types of parameters:
IDLH: Immediately Dangerous to Life or Health Concentration,

MAC: Maximum Allowable Concentration,

PC-STEL: Permissible Concentration-Short Term Exposure Limit,

PC-TWA: Permissible Concentration-Time Weighted Average.

Among the above four types of parameters, IDLH, MAC, PC-STEL indicate the short-term harm to the human body, more suitable for the risk prediction. Through the data comparison, we found IDLH use immediately threatens of life as a reference standard, so the value is higher. This paper recommends using MAC, PC-STEL value as a standard. [4]

\section{PREDICTION AND ANALYSIS OF DANGEROUS GOODS LEAKAGE IN TERMINALS}

This paper takes the prediction of a container terminal in Tianjin Port as an example. This container Terminal is located in Tianjin Port, occupying the coastline about 1441 meters, which has four berths and this terminal can dock three 200,000-ton container ships. Designed annual throughput of containers is three million TEU.

\subsection{Dangerous goods leaked into the sea}

The numerical calculation method is used to calculate the domain from south to north, The sea area verification data are taken from the hydrological data in 2012, Calculated by Mike21's MT module.

The project is a container terminal containing dangerous goods. The transportation products include a variety of soluble chemicals. According to the characteristics of transportation and toxicity, the two most representative species in the sea water quality standard are selected as representative materials. Sodium sulfide (Sea water quality standard, limit $0.02 \mathrm{mg} / \mathrm{L}$ ), and Sodium cyanide (Sea water quality standard, limit $0.005 \mathrm{mg} / \mathrm{L}$ ), the corresponding small packaging units were $0.1 \mathrm{t}$ and $0.05 \mathrm{t}$. The representative point of prediction was selected close to the edge of the dock.

Figure 1 to Figure 2 is the prediction results of the soluble chemicals leakage. It can be seen from Fig, with sodium cyanide as an example, During the rising tide period and ebb tide period, pollution range is in the harbour basin. 


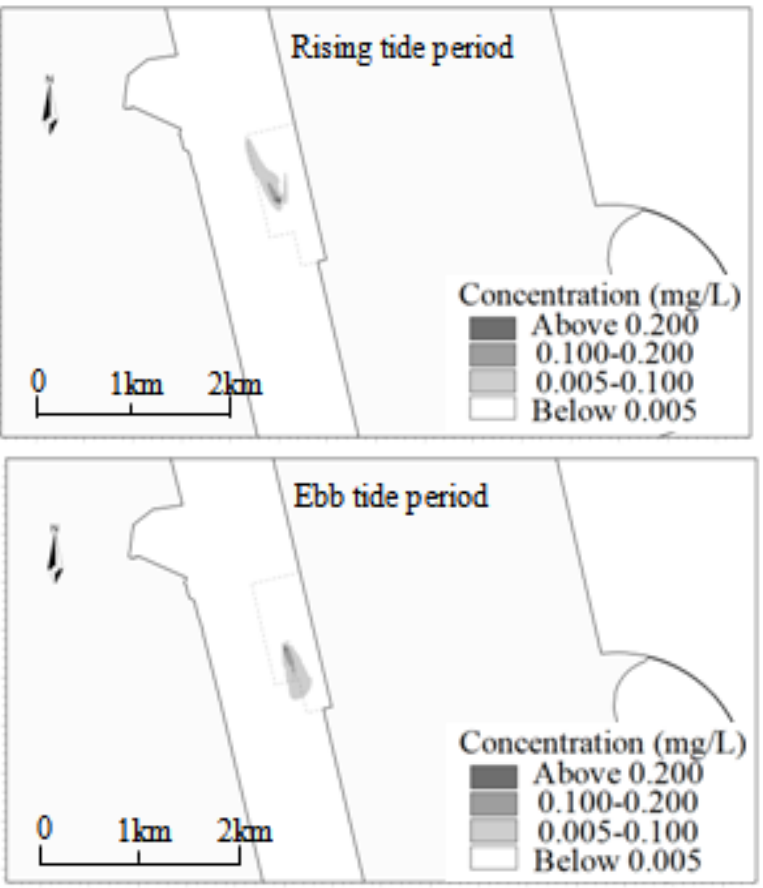

Fig 1. Pollution range of Sodium cyanide leakage near port
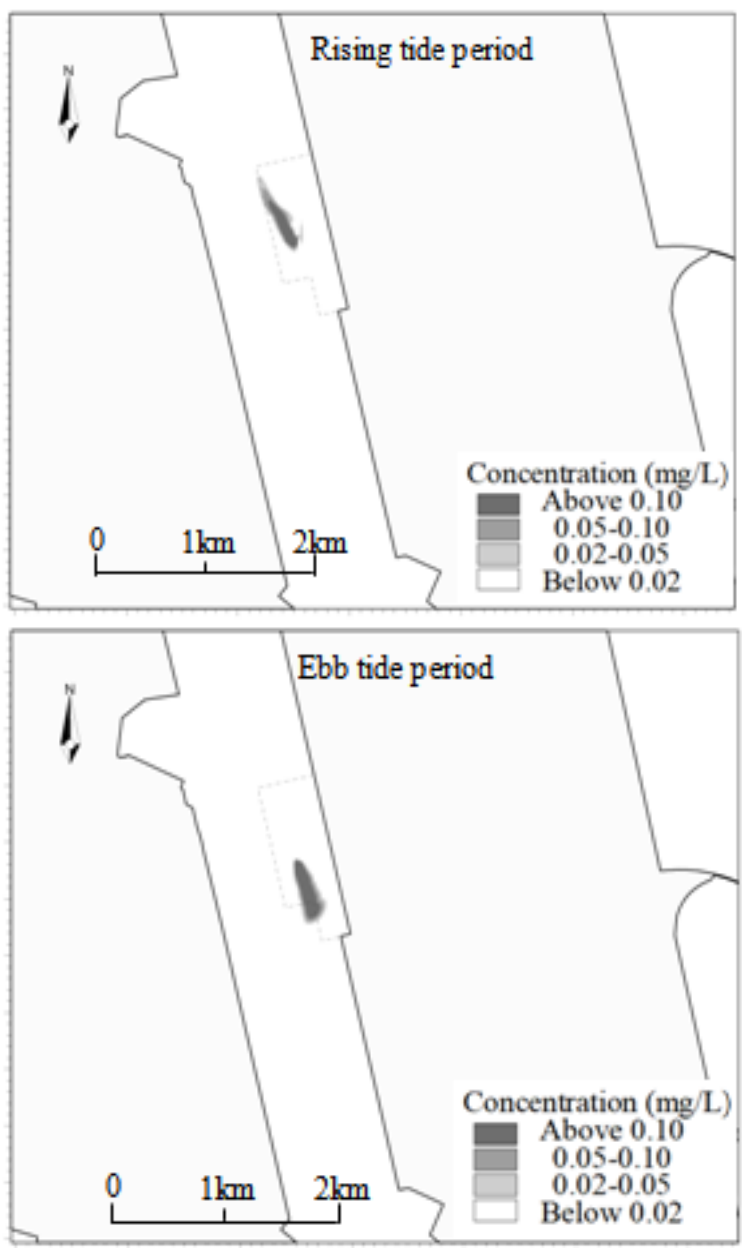

Fig 2. Pollution range of sodium sulfide leakage near port

\subsection{Gaseous dangerous goods leaked}

In order to predict the pollution extent of the volatile goods, chlorine was selected as the representative factor of gaseous substances, which was screened according to the physical and chemical properties and toxicity.[5]

According to the packaging type of liquid chlorine, the packaging density can not be higher than $1.25 \mathrm{~kg} / \mathrm{L}$, use 400L (500kg) cylinder packaging.

The average temperature of Tianjin area in July is $27^{\circ} \mathrm{C}$. The tank liquid temperature is higher than room temperature about $2 \sim 3{ }^{\circ} \mathrm{C}$, this calculation use $30{ }^{\circ} \mathrm{C}$, at this temperature, liquid chlorine cylinder pressure is generally $35.6 \mathrm{MPa}$. liquid chlorine leakage using the following formula:

$$
Q_{L G}=C_{d} A \sqrt{2 \rho_{m}\left(P-P_{C}\right)}
$$

Where:

QLG - two-phase flow leakage rate, $\mathrm{kg} / \mathrm{s}$;

$\mathrm{Cd}$ - two-phase flow leakage coefficient, 0.8 ;

A - gap area, $\mathrm{m}^{2}$;

$\mathrm{P}$ - operating pressure or container pressure, $\mathrm{Pa}$;

$\mathrm{PC}$ - critical pressure, $\mathrm{Pa}, 0.55$;

$\rho m$ - the average density of the two-phase mixture, $\mathrm{kg} / \mathrm{m}^{3}$, calculated by the following formula, $\rho \mathrm{m}=28.23$ $\mathrm{kg} / \mathrm{m}^{3}$ :

$\rho \mathrm{m}$ - the average density of the two-phase mixture, $\mathrm{kg} / \mathrm{m}^{3}$, calculated by the following formula, $\rho \mathrm{m}=28.23$ $\mathrm{kg} / \mathrm{m}^{3}$ :

$$
\rho_{m}=\frac{1}{\frac{F_{V}}{\rho_{1}}+\frac{1-F_{V}}{\rho_{2}}}
$$

Where:

$\rho 1$ - vapor density of liquid evaporation, $\mathrm{kg} / \mathrm{m}^{3}, 3.17$;

$\rho 2$ - liquid density, $\mathrm{kg} / \mathrm{m}^{3}, 1250$;

FV - the proportion of evaporated liquid to the total amount of liquid, calculated from the following formula $\mathrm{FV}=0.11$.

$$
F_{V}=\frac{C_{p}\left(T_{L G}-T_{C}\right)}{H}
$$

Where:

$\mathrm{Cp}$ - constant specific heat of two-phase mixture, J / $(\mathrm{kg} \cdot \mathrm{K}), 0.476$;

TLG - the temperature of the two-phase mixture, 303.15;

$\mathrm{TC}$ - the boiling point of the liquid at critical pressure, 238.55;

$\mathrm{H}$ - liquid gasification heat, $\mathrm{J} / \mathrm{kg}, 280$.

In general, the leakage of the liquid chlorine cylinder is small, under normal circumstances, only from the interface cracks. [6]In this case, the leakage pore size is generally less than $1 \mathrm{~cm}$. In the case of taken $1 \mathrm{~cm}$ to consider, the source of leakage are listed in the table below.

Tab 4. Source of leakage

\begin{tabular}{|c|c|c|}
\hline Accident type & $\begin{array}{c}\text { Leakage rate } \\
(\mathrm{g} / \mathrm{s})\end{array}$ & $\begin{array}{c}\text { Duration } \\
(\mathrm{s})\end{array}$ \\
\hline Interface cracks & 18.89 & 26473 \\
\hline
\end{tabular}

IDLH of chlorine was $88 \mathrm{mg} / \mathrm{m}^{3}$; MAC was $1 \mathrm{mg} / \mathrm{m}^{3}$. LC50 value (rat inhalation) is $850 \mathrm{mg} / \mathrm{m}^{3}$. 
According to the calculated results, the maximum concentration of the axis is $23.41 \mathrm{mg} / \mathrm{m}^{3}$ if the effective measures are not taken when wind speed is $1 \mathrm{~m} / \mathrm{s}$. Resulting in MAC value $\left(1 \mathrm{mg} / \mathrm{m}^{3}\right)$ the maximum pollution area of $40,400 \mathrm{~m}^{2}$; because the concentration is lower than the IDLH value $\left(88 \mathrm{mg} / \mathrm{m}^{3}\right)$, so the corresponding reference index does not exceed the standard range.

The maximum concentration of the axis is $4.71 \mathrm{mg} / \mathrm{m}^{3}$ without the effective measures when wind speed is $4 \mathrm{~m} / \mathrm{s}$, resulting in the maximum exceeding the area of $72300 \mathrm{~m}^{2}$, The concentration is lower than the IDLH value, therefore, corresponding to the reference index does not exceed the standard range.

In general, when land leakage occurred, the maximum concentration of the axis in the smaller when wind speed higher. This is due to the pollutants are easy to spread when the wind speed is high. In summary, when a land-based leakage occurs, chlorine leakage cause greater impact to the nearby location, therefore, in the toxic goods operations, the operator should wear individual protective equipment, and should formulate strict work management procedures to prevent the possibility of such accidents.

\section{CONCLUSION}

In this paper, the types of risk accidents of container terminals in transportation and loading and unloading are summarized and the screening methods of pollutant prediction source are put forward. The accident type is divided into two categories: leakage of dangerous goods and leakage of gaseous pollutants. The results of the risk screening process and the diffusion of pollutants are given for the specific projects. According to the predicted results the container operation as a clean mode of transport, without considering the "illegal business" and other subjective factors, which will not cause major pollution accidents. Under the condition of taking appropriate measure the accidents are controllable. Compared with bulk transport, this transport form is more secure and convenient.

\section{ACKNOWLEDGMENTS}

This paper is one of the phased achievements of the National Nonprofit Institute Research Grants of Tianjin Research Institute for Study on integrated Remediation technology of Immobilized microorganisms in Polluted sea water (No. TKS190408).

\section{REFERENCES}

1. Fabiano B., Currò F., Palazzi E., et al.(2002) A framework for risk assessment and decision-making strategies in dangerous good transportation. Journal of Hazardous Materials. 93(1):1-15.

2. Yan L.Y., CHEN Y.G. (2010) Study on new characteristics and the countermeasures of road transportation accident of hazardous chemicals. Journal of Safety Science and Technology. 04:65-70

3. Forigua J., Lyons L. (2016) Safety Analysis of Transportation Chain for Dangerous Goods: A Case Study in Colombia. Transportation Research Procedia. 12:842-850.

4. Alexeeff G. V., Lipsett M. J., Kizer K. W.(1989) Problems associated with the use of immediately dangerous to life and health (IDLH) values for estimating the hazard of accidental chemical releases. 50(11):598-605.

5. Qin Y. J., Li Z. X., Xia X. (2010) Study on the parameters setting and consequences simulation of chlorine leakage based on safety, Industrial Safety and Environmental Protection. 05:52-54.

6. Wang W. J., Sun B., Guo K. H. (2011) Quantitative risk analysis for LNG station accidents. Journal of Safety Science and Technology. 04:114-114. 